\title{
Supply chain operations for a circular economy
}

\author{
Luciano Batista ${ }^{1, *}$, Michael Bourlakis $^{2}$, Yang Liu $^{3}$, Palie Smart $^{4}$ and Amrik Sohal ${ }^{5}$ \\ ${ }^{1}$ Faculty of Business and Law, University of Northampton, UK \\ ${ }^{2}$ School of Management, Cranfield University, UK \\ ${ }^{3}$ Birmingham Business School, University of Birmingham, UK \\ ${ }^{4}$ School of Economics, Finance and Management, University of Bristol, UK \\ ${ }^{5}$ Monash Business School, Department of Management, Monash University, Australia
}

\begin{abstract}
This editorial piece introduces the aim and content of the special issue on Supply Chain Operations for a Circular Economy. We initially provide an overview of the special issue themes and related inter-disciplinary topics. A summary of the accepted papers is presented in terms of the specific topics they address and their main contributions to the domain of supply chain operations. The discussions illustrate a breadth of theoretical perspectives and practical approaches considered by the academic community in addressing real world phenomena related to this special issue. The editorial piece concludes by identifying future research directions that seek to develop knowledge and understanding about circular economy operations, principles, praxis and theoretical advances.
\end{abstract}

Keywords: circular supply chain; circular economy; sustainable operations.

\section{Introduction}

Supply chain management provides significant opportunities to enable business approaches to meeting sustainability imperatives of the so-called 'circular economy'. Strong cases have been made for the circular use of resources by businesses as a response to the rising costs of raw materials acquisition and the environmental impact of by-products and waste handling and disposal (Preston 2012; Svensson and Wagner 2012; Su et al. 2013; Bourlakis et al. 2014; Smart et al. 2017).

The 'circularity' feature of supply chains relates to an increase in the rate of remanufacturing, reuse and recycling processes in the economy. The progressive adoption of 'circular' supply chains (Dervojeda et al. 2014) seeks to incorporate notions of industrial symbiosis, eco-systems services, resource-based productivity and fundamental alignment to sustainability issues (Chertow 2007; Seuring and Müller 2008; Sarkar 2013). The shift from linear production chains to circular systems requires business models that streamline circular flows not only of products, but also of byproducts and waste materials across similar or diverse industries (Loomba and Nakashima 2012). Such circular models involve networks of businesses that generate new economic value through the continuous exchange of resources facilitated by innovative logistics and supply chain ecosystems. Furthermore, they can help materially deficient communities and nations by delivering growth in material wellbeing while at the same time reducing demands on the planet's resource capacity (Hsu et al. 2013).

\footnotetext{
* Corresponding author.

Cottesbrooke Building, Boughton Green Road, Northampton, NN2 7AL. Telephone: +44 (0)1604 893

685, Email: Luciano.Batista@northampton.ac.uk
} 
The increased complexity and expanded scope of circular supply chain operations and their role as enablers of business responses to sustainability imperatives deserve a more comprehensive understanding and debate. Beyond the typical flow of products, circular chains also involve inter-firm linkages that take into account the utilisation of waste and by-products as feedstock to further production processes (Chertow 2012). Industrial connections of this nature are crucial in a circular economy, where existing input-output flows of materials are complemented by further production and consumption cycles in which undesired outputs are used as valuable inputs. Such circular flow of resources are in practice enabled by logistics and supply chain operations that facilitate recovery, reuse and recycling loops as preferable alternatives to disposal (EM Foundation 2014).

Indeed, over the last decade many businesses have been gradually transforming disposal streams of used materials, by-products and waste into streams of high-value products (Esty and Simmons 2011; Lovins and Braungart 2014). Such trends are shaping the emergence of recycling and waste management innovations, the growth of remanufacturing operations and secondary goods market, and the development of circular supply chain models where businesses from diverse sectors (profit and nonprofit) play a more interactive and collaborative role (EM Foundation 2013; Webster 2015).

Although the circular economy approach has gained increased prominence in academic, practitioner and policy circles, its actual enactment is still limited and fragile (Gregson et al. 2015). The transition to a circular economy based upon circular design and production, circular business models involving recovery of products/byproducts/waste, and cross-sector collaborations beyond traditional supply chain boundaries (Dervojeda et al. 2014; WEF 2014), requires a refreshed understanding of managerial aspects concerning supply chain operations in this complex context.

There is momentum for bringing theory and practice forward by revisiting extant supply chain management approaches in the light of the circular models needed today. In this respect, emerging circular supply chain concepts and models are expected to address the increased complexity of the current business context by taking into account the wider scope of material flows, i.e. circular flows not only of products, but also of by-products and waste, across organisations from similar and diverse sectors. This is a fertile area for research calling for updated perspectives, views, conceptual frameworks, managerial tools, strategies and operational practices regarding the role that circular supply chains can play in enabling business innovations based upon circular economy principles and praxis.

Accordingly, this special issue called for academics, practitioners and thought leaders to submit manuscripts that bring forward and better position supply chain management into the circular economy context, this way providing a more comprehensive and up-to-date contribution to the wider debate on how businesses and their related supply chains meet the challenges of sustainability.

Based on the contextual background presented above, the thematic scope of this special issue was defined to engage a variety of research types and questions in this burgeoning field: literature reviews; competitive strategy; business models; environmental strategy; supply chain design; supply chain collaboration; legislation drivers; sustainability drivers; operational barriers; business practices; and contextual/regional studies. With basis on these aspects, we specified the related topics that provided a more specific referential ground for the matters particularly concerning 
the special issue and its remit, as shown in Table 1.

Table 1. Topics in the special issue call for papers

\begin{tabular}{|l|l|}
\hline Topic & $\begin{array}{l}\text { Main research } \\
\text { perspective }\end{array}$ \\
\hline $\begin{array}{l}\text { Critical review of current theory and practice in logistics and supply } \\
\text { chain management in the light of circular flows of products, by- } \\
\text { products and waste materials. }\end{array}$ & $\begin{array}{l}\text { Literature review; } \\
\text { theoretical } \\
\text { fundamentals }\end{array}$ \\
\hline $\begin{array}{l}\text { The design of circular supply chains accommodating small local } \\
\text { enterprises, corporate players and informal actors in circular supply } \\
\text { chain configuration ecosystems. }\end{array}$ & Supply chain design \\
\hline $\begin{array}{l}\text { Implementation of product and/or by-product synergy systems } \\
\text { through circular supply chains. }\end{array}$ & $\begin{array}{l}\text { Supply chain } \\
\text { collaboration }\end{array}$ \\
\hline $\begin{array}{l}\text { Opportunity oriented strategies or new business models enabled by } \\
\text { circular supply chains of products, by-products and waste materials. }\end{array}$ & $\begin{array}{l}\text { Competitive strategy; } \\
\text { Business models }\end{array}$ \\
\hline $\begin{array}{l}\text { Corporate responses to climate change and scarcity of natural } \\
\text { resources through circular supply chain operations. }\end{array}$ & $\begin{array}{l}\text { Environmental } \\
\text { strategy }\end{array}$ \\
\hline $\begin{array}{l}\text { Environmental regulations and constraining factors influencing the } \\
\text { implementation of by-products and waste supply chains. }\end{array}$ & Legislation drivers \\
\hline $\begin{array}{l}\text { The main drivers and socio-economic-environmental benefits of } \\
\text { circular supply chains. }\end{array}$ & Sustainability drivers \\
\hline Challenges and barriers of circular supply chain implementation. & Operational barriers \\
\hline $\begin{array}{l}\text { Exploratory studies on circular supply chains based on circular } \\
\text { economy practices. }\end{array}$ & Business practices \\
\hline $\begin{array}{l}\text { Circular supply chain initiatives in developing, emerging and } \\
\text { developed markets. }\end{array}$ & Regional studies \\
\hline
\end{tabular}

The topics listed in Table 1 set the scene for the special issue and were put forward to the academic community through the call for papers. The response from the community was substantive, resulting in 38 manuscript submissions. From this total, 29 manuscripts have gone through a double review process. With the support of reviewers with expertise in the various knowledge areas of the special issue, 10 papers that more closely addressed the special issue topics were finally accepted. An overview of the contributing papers is provided in the subsequent sections.

\section{Overview of the special issue contributions}

The papers in this special issue reflect the increasing relevance of the special issue theme for academics and practitioners. They offer a broad variety of research directions, methodologies and useful theoretical and practical insights in the field. Intentionally, we did not limit the methodological approaches of the research reported and included conceptual papers in the mix, so that we could compile a more complete picture of the latest research perspectives in this continually growing field. Table 2 lists the 10 papers comprising the special issue and their respective research perspectives. We have 
organised the papers in a sequence that develops the following subject order logic: theoretical basis (literature reviews and theoretical fundaments), strategic aspects (competitiveness, design and collaboration), and implementation aspects (business models, practices, drivers and barriers).

Table 2. Papers in the special issue and their related research perspective

\begin{tabular}{|c|c|}
\hline $\begin{array}{l}\text { Authors } \\
\text { Paper title }\end{array}$ & $\begin{array}{l}\text { Research } \\
\text { perspective }\end{array}$ \\
\hline $\begin{array}{l}\text { De Angelis, Howard and Miemczyk } \\
\text { Supply Chain Management and the Circular Economy: Towards the } \\
\text { Circular Supply Chain }\end{array}$ & $\begin{array}{l}\text { Literature review; } \\
\text { theoretical } \\
\text { fundamentals }\end{array}$ \\
\hline $\begin{array}{l}\text { Batista et al. } \\
\text { In Search of a Circular Supply Chain Archetype - A Content- } \\
\text { Analysis-Based Literature Review }\end{array}$ & $\begin{array}{l}\text { Literature review; } \\
\text { theoretical } \\
\text { fundamentals }\end{array}$ \\
\hline $\begin{array}{l}\text { Larsen et al. } \\
\text { How the reverse supply chain contributes to a firm's competitive } \\
\text { strategy: a strategic alignment perspective }\end{array}$ & Competitive strategy \\
\hline $\begin{array}{l}\text { Srai et al. } \\
\text { Circular supply chains and renewable chemical feedstocks: A } \\
\text { network configuration analysis framework }\end{array}$ & Supply chain design \\
\hline $\begin{array}{l}\text { Bernon, Tjahjono and Ripanti } \\
\text { Aligning Retail Reverse Logistics Practice with Circular Economy } \\
\text { Values: An Exploratory Framework }\end{array}$ & $\begin{array}{l}\text { Supply chain design; } \\
\text { Supply chain } \\
\text { collaboration }\end{array}$ \\
\hline $\begin{array}{l}\text { Yang et al. } \\
\text { Product-service systems business models for circular supply chains }\end{array}$ & Business models \\
\hline $\begin{array}{l}\text { Mishra, Hopkinson and Tidridge } \\
\text { Value Creation from Circular Economy led Closed Loop Supply } \\
\text { Chains: A Case Study of Fast Moving Consumer Goods }\end{array}$ & Business models \\
\hline $\begin{array}{l}\text { Vlajic, Mijailovic and Bogdanova } \\
\text { Creating loops with value recovery: empirical study of fresh food } \\
\text { supply chains }\end{array}$ & $\begin{array}{l}\text { Business models; } \\
\text { Business practices }\end{array}$ \\
\hline $\begin{array}{l}\text { Masi et al. } \\
\text { Towards a more circular economy: Exploring the awareness, } \\
\text { practices, and barriers from a focal firm perspective }\end{array}$ & $\begin{array}{l}\text { Business practices; } \\
\text { Sustainability drivers; } \\
\text { Operational barriers; }\end{array}$ \\
\hline $\begin{array}{l}\text { Mangla et al. } \\
\text { Barriers to effective circular supply chain management in a } \\
\text { developing country context }\end{array}$ & $\begin{array}{l}\text { Operational barriers; } \\
\text { Regional studies }\end{array}$ \\
\hline
\end{tabular}

\subsection{Particular contributions of the papers}

The paper by De Angelis, Howard and Miemczyk explores supply chain management (SCM) implications to circular supply chains (CSCs). Based upon a literature review, the authors conclude that the academic literature on the circular economy (CE) gives little attention to supply chain management implications, i.e. the literature on the 
circular economy is fragmented and spread across a number of more established fields, giving limited attention to implementation and the implications for business models and related supply chains. Overall, they arrive to the conclusion that there is a lack of literature bridging CE and SCM and there is very little information on the practical side of how to introduce CSCs in a real-world context. To address this gap, the authors derive from literature some preliminary propositions concerning implications for the development of the term 'circular supply chains' (CSCs), which they see as the embodiment of circular economy principles within supply chain management. The five specific propositions developed in the paper are:

P1. Supply chain relationships will change in CSCs, shifting from product ownership towards greater emphasis on leasing and service-based strategies enabled by digital systems

$\mathrm{P} 2$. CSCs requires structural flexibility and reduced geographic barriers with SMEs and innovators within regional/local loops playing an important role in their implementation

P3. CSCs must consider both closed and open material loops in technical and biological cycles.

P4. CSCs are enabled by close supply chain collaboration with partners within and beyond their immediate industrial boundaries, including suppliers, product designers and regulators.

P5. Procurement policies, both in the private and public sectors of service organisations, are an important lever for the transition to CSCs if they go beyond minimum legal requirements to include the $\mathrm{CE}$ principles.

In their paper, Batista et al. position supply chain operations in the CE context. To this end, they address questions of how extant research discourses concerning the sustainability of supply chains contribute to the understanding of 'circularity' features in supply chain configurations that support restorative and regenerative material flows, as espoused by the CE ideal. The authors develop a content-based literature analysis that leads to a theoretical foundation of a circular supply chain. They derive an archetypal form of a circular supply chain from four antecedent sustainable supply chain narratives that are predominant in the area, namely: 'reverse logistics', 'green supply chains', 'sustainable supply chain management' and 'closed-loop supply chains'. The paper offers five propositions on what the circular supply chain archetype represents in terms of its scope, focus and impact. Novel insights lead to the definition of a circular supply chain and the specification a more coherent theoretical underpinning of the subject for future inquiry and practice. The five propositions developed in the paper are:

P1. Circular supply chains represent an expansion of the closed-loop narrative of sustainable supply chains in terms of scope and focus of the value chain systems they consider.

P2. Circular supply chains extend the boundaries of closed-loop supply chains by taking into account post-production stewardship to include forward feeding flows into alternative supply chains.

P3. Circular supply chains support sustainable value chain systems derived not only from products and their end of life returns, but also from associated by-product synergies, services and waste flows. 
P4. In a circular supply chain, inner loops involve restorative and regenerative processes that minimise (re)processing of materials/resources.

P5. Circular supply chains should be designed to maximise restorative and regenerative processes downstream.

The paper by Larsen et al. addresses the role that reverse supply chains (RSC) can play in the competitive strategy of organisations. To this end, the paper explores the alignment between the RSC and the competitive strategy of the firm. The authors investigate potential strategic, tactical, and operational roles of RSCs in the context of seven original equipment manufacturer (OEM) firms. They arrive at the conclusion that the firms do not exploit the full potential of RSCs to reinforce their competitive strategy and the conditions allowing exploitation remain unclear. In the study, the authors see RSCs as supply chains that are conceptually different from 'reverse logistics', in a much wider sense. In their view, RSCs include all usual types of reverse logistics activities as well as activities such as the handling of waste, which includes the recovery of residual value that can play a pivotal role in determining the competitive advantage of the firms. The authors link the topic with the circular economy context by arguing that RSCs can potentially promote a stronger focus on the design of regenerative supply chains that are in line with circular economy principles.

A circular supply chain design perspective is considered by Srai et al., who apply circular supply chain concepts to explore commercially viable network configurations for the use of renewable chemical feedstocks (RCFs). The authors develop a decisionmaking framework to support supply chain design and management processes that aggregate value to RCFs and by-products. The framework takes into account the characteristics of the renewable chemical feedstock and related technological, market, value, and viability factors. They acknowledge that the circular economy paradigm can inform an integrated assessment approach where the analysis of feedstock sources, processing technologies and resulting intermediates or end-products can be undertaken in a systematic manner. The transition from petroleum-based feedstocks to renewable alternatives in a viable manner is an example of the circular economy approach considered in sustainable supply chain management. From this context, the paper highlights the significance of RCFs due to their emerging potential to replace petrochemicals. They conclude that the lack of effective CSC analysis tools is evident and, as a result, the potential to use industrial waste streams is often not exploited adequately.

In their paper, Bernon, Tjahjono and Ripanti explore better ways in which Retail Reverse Logistics (RRL) engages with the circular economy. The authors point out that whilst there is an increasing awareness of the need for a CE approach, many companies have little appreciation of how the values of CE can be utilised or embedded in their reverse logistics practices. They therefore propose a conceptual framework that supports the adoption of CE values, i.e. a framework for aligning RRL and CE that takes into account the alignment between RRL/CE and Sustainability Agenda; between RRL/CE and Product Portfolio; between RRL/CE and Supply Chain Integration; between RRL/CE and Compliance Regulation; between RRL/CE and Customer-Centricity; and between RRL/CE and Collaboration. The study has found that many managers consider $\mathrm{CE}$ as an extension to their sustainability or green agenda and there is consensus that $\mathrm{CE}$ needs to be positioned within their organisations' overall CSR (Corporate Social Responsibility) programme. The authors also found that embedding CE values within 
RRL necessitates the adoption of a multi-faceted approach. Accordingly, the paper makes a novel contribution by presenting a multi-dimensional approach embedding CE values in RRL operations.

The paper by Yang et al. explores the relationship between business model innovations and the phenomenon of 'circularity' in supply chain operations. Business model innovations for circularity are analysed with a focus on the four sources of value creation based on core circular economy practices, i.e. value creation involving inner circles, circling longer, cascaded use and pure circles. The research comprises an exploratory case study of a large Chinese manufacturing firm operating a traditional product-based business model and three variants of product-service systems (PSS), namely: product-oriented, use-oriented and result-oriented PSSs. The authors suggest that PSS business models can enhance restorative and regenerative effects of inner circles, circling long and cascading use circles. Their findings show that PSS business models that are result oriented demonstrate tighter and more efficient circularity of supply chain operations.

The paper by Mishra, Hopkinson and Tidridge explores the role of closed loop supply chains (CLSC) in creating and recovering value from recovery supply chain processes in the fast moving consumer goods (FMCG) sector. The authors see a circular supply chain as circular economy-led (CE-led) CLSC. The paper identifies key challenges and building blocks of value creation from CE-led closed-loops. More specifically, the research involves analysis of four CE-led closed-loop case examples from a major European FMCG company. The study assesses how these cases create value, for whom value is created, and key CLSC implementation challenges. The paper seeks to provide a better understanding of consumer responses to remanufactured goods, and the relationship between product design and recovery activities. The authors propose the term 'circular supply chain' (CSC) for cases where circular economy principles are explicitly incorporated in CLSC for value creation. They see CSC management as an integrated approach to generating economic, social and environmental value, which intersects with shared value approaches, sustainable business models and whole system value frameworks. The authors reach the conclusion that creating successful value propositions from CE-led closed-loop approaches is complex and requires simultaneous reconfiguration of key business model building blocks to ensure customer acceptance and business viability.

The study of Vlajic, Mijailovic and Bogdanova focuses on fresh food supply chains. The authors claim that there is a need for the development of a circular supply chain concept that considers value recovery in the context of circular flows, as well as those elements that might affect their creation. Accordingly, their research investigates the current state of value recovery practices as a part of circular food supply chains. The authors see value recovery processes as an integral part of circular flows. An interesting perspective of this research is the consideration of remanufacturing in the study of fresh food supply chains. The authors argue that although recovery processes are considered in multiple studies about food waste, remanufacturing did not receive sufficient attention in the literature on waste management, reverse logistics, and closed-loop supply chain. They therefore offer specific insights on remanufacturing in the context of SMEs and food supply chains. The study analyses three food networks regarding the nature of circular flows, as well as factors that affect their creation. The value recovery of the circular flows identified is analysed on the basis of the product residual value, the quantities available for recovery, the overall value from the recovery, and the markets for recovered products. The authors reach the conclusion that the financial value from 
recovery is a necessary condition for the operations profitability of value recovery processes in fresh food supply chains, but not for the occurrence of the corresponding loop itself. They also conclude that reuse and remanufacturing loops likely feed into alternative markets, while recycling loops likely feed back into fresh food supply chains.

The outcomes of an exploratory survey are presented in the paper by Masi et al. The authors investigate organisational shifts towards the CE. The survey involved 77 organisations that are related to relevant subject areas such as sustainability, green practices, circular economy, manufacturing, business excellence and operations management. The implementation of organisational practices within these areas are investigated in terms of their alignment with CE principles at focal firm level as well as across the broader supply chain (upstream and downstream). The authors identify barriers hindering the implementation of the investigated practices and use a taxonomy of practices and barriers. Their results show that firms favour practices involving resource and energy utilisation efficiency, while practices related to investment recovery, green purchasing and customer cooperation are less prevalent. Eco-design and internal environmental management practices have a medium level of implementation. Further results suggest that the implementation of $\mathrm{CE}$ practices is mostly driven by economic rather than environmental considerations, and the deployment of CE practices remains mainly within a firm rather than across the supply chain. In terms of economically driven practices, there is a marked preference for practices that generate an economic return in the short-term. Significant up-front investment costs and lack of awareness or sense of urgency are identified as main implementation barriers. The research findings also highlight that companies prefer practices at the firm level rather than supply chain level initiatives.

Operational barriers and regional perspectives are considered in the study by Mangla et al. Specifically, the authors identify barriers to circular supply chain management (CSCM) adoption in the Indian context, including identification of the contextual interactions among the identified barriers and examination of their hierarchical levels in terms of effective CSCM adoption and implementation. They apply an integrated Interpretive Structural Modelling - MICMAC approach to analyse data collected from five automotive manufacturing companies from the northern region of India. The lack of regulatory policies, technological knowhow and modern infrastructure are identified as potential barriers to adopt CSCM in India. Lack of stakeholder's environmental awareness is also mentioned as a discouraging factor for the implementation of circular supply chain models in the country. The authors discuss policy aspects and propose recommendations to assist managers and government bodies to adopt and manage the concepts of circular supply chains more effectively in India.

\section{Conclusion}

This special issue uncovers latest theoretical and practical knowledge that provide valuable insights for academics and practitioners concerned with better positioning sustainable supply chain management in the circular economy context. The manuscripts that comprise the special issue demonstrate the interdisciplinary nature of research addressing sustainable supply chain operations in the circular economy context.

Although the ten papers that appear in this special issue present a good variety of relevant topics and research perspectives applied in the field, they are far from stressing the whole range of research approaches and managerial issues in the area. For instance, 
the special issue papers do not cover research on environmental corporate strategies and legislation drivers shaping the implementation of circular supply chains. We therefore reinforce our call for research on corporate responses to climate change and scarcity of natural resources through circular supply chain operations. Future research on this area could address, for example, how circular economy principles and practices influence the development of environmental strategies and the role of circular supply chains in supporting the implementation of such strategies. We also emphasise the call for research on environmental regulations influencing the adoption of more sustainable business practices and supporting circular supply chain operations. The political and legal landscape is fundamental in promoting and strengthening the shift to more sustainable production and consumption systems espoused by the circular economy. Future research in this area could address issues such as how a strong policy and regulation framework affects the adoption of more sustainable production and supply chain operations aligned with responsible business and societal growth.

Nonetheless, altogether the papers in this special issue make valuable contributions to advancing knowledge in the field. We expect that this focused issue will stimulate continued interest in the area and will provide the academic community with new insights for pursuing further research concerning circular supply chain operations in the circular economy.

\section{Acknowledgments}

The guest editors of this special issue are grateful to all reviewers for their valuable contributions in reviewing the papers. We are also grateful to the journal editors, Professor Stephen Childe and Professor Bjørn Andersen, and the editorial and publishing team for their continuous support. Finally, we also thank the authors who submitted their work for consideration in this special issue. We had many submissions of high quality. Unfortunately, due to limited publication space, the editorial team selected only the manuscripts that more closely addressed the special issue topics.

\section{References}

Bourlakis, Michael, George Maglaras, David Gallear, and Christos Fotopoulos. 2014.

"Examining Sustainability Performance in the Supply Chain: The Case of the Greek

Dairy Sector." Industrial Marketing Management 43 (1): 56-66.

doi:10.1016/j.indmarman.2013.08.002.

Chertow, Marian R. 2007. “Uncovering' Industrial Symbiosis.” Journal of Industrial

Ecology 11 (1): 11-30. doi:10.1162/jiec.2007.1110.

. 2012. "Industrial Symbiosis." The Encyclopedia of Earth.

http://www.eoearth.org/view/article/153824/.

Dervojeda, K, D Verzij1, E Rouwmaat, L Probst, and L Frideres. 2014. "Clean

Technologies - Circular Supply Chains." EU Directorate-General for Enterprise and Industry, Brussels: European Union.

EM Foundation. 2013. “Towards the Circular Economy: Economyc and Business 
Rationale for Accelerated Transition." Journal of Industrial Ecology 1 (1): 4-8. doi:10.1162/108819806775545321.

. 2014. "Towards the Circular Economy - Volume 3: Accelerating the Scale-up across Global Supply Chains." Ellen MacArthur Foundation Report, Cowes, Isle of Wight.

Esty, Daniel C., and P. J. Simmons. 2011. The Green to Gold Business Playbook: How to Implement Sustainability Practices for Bottom-Line Results in Every Business Function. New Jersey: Wiley.

Gregson, Nicky, Mike Crang, Sara Fuller, and Helen Holmes. 2015. "Interrogating the Circular Economy: The Moral Economy of Resource Recovery in the EU." Economy and Society 44 (2): 218-43. doi:10.1080/03085147.2015.1013353.

Hsu, Chin- Chun, Keah Choon Tan, Suhaiza Hanim Mohamad Zailani, and Vaidyanathan Jayaraman. 2013. "Supply Chain Drivers That Foster the Development of Green Initiatives in an Emerging Economy." International Journal of Operations \& Production Management 33 (6). Emerald Group Publishing Limited: 656-88. doi:10.1108/IJOPM-10-2011-0401.

Loomba, Arvinder P.S., and Kenichi Nakashima. 2012. "Enhancing Value in Reverse Supply Chains by Sorting before Product Recovery." Production Planning \& Control 23 (2-3). Taylor \& Francis Group: 205-15. doi:10.1080/09537287.2011.591652.

Lovins, Amory, and Michael Braungart. 2014. A New Dynamic - Effective Business in a Circular Economy. 2nd ed. Cowes, Isle of Wight: Ellen MacArthur Foundation Publishing.

Preston, Felix. 2012. "A Global Redesign? Shaping the Circular Economy." Energy, Environment and Resource Governance, no. March: 20. http://www.chathamhouse.org/sites/files/chathamhouse/public/Research/Energy, Environment and Development/bp0312_preston.pdf.

Sarkar, A.N. 2013. "Promoting Eco-Innovations to Leverage Sustainable Development of Eco-Industry and Green Growth.” European Journal of Sustainable Development 2 (1): 171-224. doi:10.14207/ejsd.2013.v2n1p171.

Seuring, Stefan, and Martin Müller. 2008. "From a Literature Review to a Conceptual Framework for Sustainable Supply Chain Management." Journal of Cleaner Production 16 (15): 1699-1710. doi:10.1016/j.jclepro.2008.04.020.

Smart, Palie, Stefan Hemel, Fiona Lettice, Richard Adams, and Stephen Evans. 2017. "Pre-Paradigmatic Status of Industrial Sustainability: A Systematic Review." International Journal of Operations \& Production Management 37 (10). Emerald Publishing Limited : 1425-50. doi:10.1108/IJOPM-02-2016-0058. 
Su, Biwei, Almas Heshmati, Yong Geng, and Xiaoman Yu. 2013. "A Review of the Circular Economy in China: Moving from Rhetoric to Implementation." Journal of Cleaner Production 42 (March): 215-27. doi:10.1016/j.jclepro.2012.11.020.

Svensson, Göran, and Beverly Wagner. 2012. "Implementation of a Sustainable Business Cycle: The Case of a Swedish Dairy Producer.” Edited by Assistant. Supply Chain Management: An International Journal 17 (1). Emerald Group Publishing Limited: 93-97. doi:10.1108/13598541211212230.

Webster, Ken. 2015. The Circular Economy - a Wealth of Flows. Cowes, Isle of Wight: Ellen MacArthur Foundation Publishing.

WEF. 2014. "Towards the Circular Economy: Accelerating the Scale-up across Global Supply Chains." World Economic Forum Report, Geneva. 